\title{
ARANCEL DE REFERENCIA V/S ARANCEL REAL: DIAGNÓSTICO E INTERROGANTES INICIALES
}

\section{Introducción}

El cobro de aranceles por parte de las instituciones de educación superior constituye una característica distintiva del sistema chileno desde hace ya décadas. Con independencia de la propiedad de los centros educativos, cada uno de ellos fija, año tras año, y autónomamente, el precio que debe pagar un individuo (o quien lo beque o le dé crédito) por cursar un programa de formación. Ello, sumado al incremento acelerado de la oferta en términos de instituciones, sedes, vacantes y carreras, ubica a Chile entre los países con mayor gasto privado en educación superior y uno de los lugares ideales para explorar el comportamiento de lo que se ha llamado "mercado de la educación".

Resulta interesante, en este contexto, examinar los valores de los aranceles de las carreras actualmente ofrecidas en el sistema de educación superior, en la medida en que constituyen el precio que los usuarios están dispuestos a pagar por la entrega de un servicio educativo y, por lo tanto, su determinación no es casual ni azarosa.

En ello están en juego los mecanismos de mercado, pero también elementos como las valoraciones sociales y las expectativas de individuos y grupos sociales. Y especialmente en el caso de la educación, no podría ser de otro modo, pues no es un asunto neutral en la medida en que es concebido como un derecho de todas las personas, a pesar de que opere con mecanismos de mercado. En efecto, la exigencia de pagar un arancel a cambio de recibir educación superior tiene un gran costo social y supone un factor de discriminación al marginar a quienes, por escasez de recursos, no pueden financiarlo. 
Por lo tanto, el costo de la educación es un tópico que, además de ser objeto de análisis de mercado, está frecuentemente en la discusión pública y teñido, además, de elementos éticos e incluso emocionales. Su debate se aviva aún más a principios de cada año, a partir de las denuncias sobre alzas sistemáticas en el valor de los aranceles de distintas casas de estudio y los datos publicados tanto por organismos públicos como por centros de investigación, que confirmarían dicho incremento. En enero de 2006, el Ministerio de Educación (MINEDUC) acusaba, a través de los medios de comunicación, alzas de los aranceles que alcanzaban hasta un 19\% entre un año y el siguiente, y varios rectores desmentían las cifras. Ya en 2003, un estudio del Departamento de Economía de la Universidad de Santiago de Chile, concluía que todo el sistema universitario elevó sus aranceles, en promedio, un 47\% entre 1995 y 2002, y sus autores afirmaban que la tendencia al alza se mantendría, dado que las personas aspiraban cada vez más a una formación universitaria.

Este año se agregó un nuevo factor de polémica debido a la fijación de aranceles de referencia por parte del MINEDUC para la asignación de créditos para los estudiantes. Dichos aranceles referenciales fueron construidos sobre la base de algunos indicadores de funcionamiento de instituciones de educación superior, como su calidad académica y la eficacia de su docencia. Por lo tanto, observamos también que es objeto de políticas públicas y que el Estado se está involucrando indirectamente en el tema de los valores de los aranceles para efectos de asignar financiamiento, enviando de paso un mensaje acerca de la relación entre tales aranceles y algunos indicadores de docencia de las instituciones, vale decir, una señal sobre la asociación entre precio y calidad (más allá de las objeciones que puedan formularse a los indicadores particulares escogidos por el Ministerio).

Ante esto ha surgido la controversia, por una parte, acerca de la metodología que siguió el MINEDUC para determinar los valores de referencia, la que, por sus indicadores, supone una opción 
por una determinada noción de calidad educativa, y, por otra, acerca de las consecuencias que se generarían por el hecho de que, en muchos casos, los aranceles exigidos en la realidad sean mayores que el arancel de referencia que cubren los créditos. Esta última situación afecta directamente a las casas de estudios y a los estudiantes sujetos de crédito, pues entre estos dos agentes queda entonces el conflicto de decidir quién asumirá la diferencia, en la medida en que ésta no será cubierta por el Estado ni por la banca privada. Inicialmente, a partir de un compromiso establecido entre el Ministerio y el Consejo de Rectores de las Universidades Chilenas $(\mathrm{CRUCH})$, la mayoría de las universidades adscritas a este último financiarían la diferencia con crédito propio de iguales condiciones que el del Fondo Solidario.

Habrá que ver cómo se irán resolviendo estas situaciones y si las recientes modificaciones al esquema de ayudas estudiantiles impactarán en el comportamiento de los precios, para lo cual se requerirían otros diseños de investigación que abordaran ese tema una vez producidos los efectos en el sistema.

De momento, sin embargo, hay un valor en aprovechar la información disponible, justamente para avanzar en una línea descriptiva que dé cuenta de la situación real, más allá de las declaraciones e impresiones acerca del sistema de ayudas para financiar estudios superiores. En este sentido, importa conocer cuál es la magnitud real de la brecha entre los aranceles reales y el arancel de referencia y, si ella existe, en qué instituciones y en qué carreras es mayor o más frecuente. Es interesante, además, porque, de los antecedentes revisados, como informes, columnas y noticias en los medios de comunicación, es posible apreciar un sinnúmero de afirmaciones y apreciaciones de distintos actores a favor y en contra de la fijación de valores referenciales, sin que se haya mencionado un estudio que realice la comparación sistemática del valor referencial y el valor real a través de un diagnóstico completo. En consecuencia, este estudio espera servir, en alguna medida, para confirmar o bien para matizar algunos de estos dichos. 


\section{Definiciones y consideraciones metodológicas}

Considerando lo anterior, el objetivo general de este estudio es determinar si existe una brecha entre los aranceles cobrados por las instituciones de educación superior y los valores de referencia fijados por el MINEDUC, y cuál es su magnitud según tipo de instituciones y carreras.

En vista de este objetivo, fue necesario constituir estas dos variables: el arancel de referencia de una determinada carrera en una determinada institución y el arancel real cobrado en el primer semestre de 2006 por dicha institución en esa carrera.

\section{Acerca de los aranceles de referencia}

Son valores referenciales que el MINEDUC ha establecido para la asignación de los montos de los créditos que se otorgan a los estudiantes para financiar sus estudios superiores, particularmente para el Fondo Solidario de Crédito Universitario y para el nuevo Crédito con Garantía Estatal. En términos concretos, los créditos entregados permiten cubrir el 100\% del arancel de la carrera de los estudiantes seleccionados, teniendo como tope el arancel de referencia definido para la respectiva carrera. Por lo tanto, no cubre las eventuales diferencias entre los valores referenciales y los reales.

Según lo informado por el Ministerio acerca de la construcción de estos aranceles, un primer modelo para su fijación fue elaborado durante 2005, precisándose que se trata de uno de transición que será revisado anualmente en un trabajo conjunto de dicho Ministerio con el CRUCH.

De acuerdo con el informe aportado por el MINEDUC que describe dicho modelo, en la primera etapa de implementación de este esquema de financiamiento (entre 2006 y 2010), el cálculo del arancel de referencia contempla inicialmente un agrupamiento de instituciones a partir de indicadores de nivel institucional, esto es: 
- Indicadores académicos, con información sobre el número de jornadas completas equivalentes con doctorado y magíster, el número de proyectos FONDECYT ${ }^{\mathrm{i}}$ y de publicaciones ISI ${ }^{\mathrm{ii}}$ y SciELO ${ }^{\mathrm{iii}}$.

- Eficiencia docente, indicada con tasa de titulación (porcentaje de estudiantes que se titula en los años de duración declarada de la carrera, más un año) y con tasa de retención en primer año (porcentaje de alumnos que permanece en la carrera).

- Acreditación, expresada en número de años de acreditación de la institución, indicador que se emplea para determinar el arancel de referencia del grupo.

A partir de ello, fueron establecidos cuatro grupos de instituciones, cuya composición puede ir variando de acuerdo con el comportamiento de sus indicadores. De la aplicación de esta fórmula se obtuvo una primera distribución de universidades, institutos profesionales y centros de formación técnica.

\begin{tabular}{cllll}
\hline GRUPO & \multicolumn{1}{c}{$\begin{array}{c}\text { UNIVERSIDADES } \\
\text { CRUCH }\end{array}$} & \multicolumn{1}{c}{$\begin{array}{c}\text { UNIVERSIDADES } \\
\text { PRIVADAS }\end{array}$} & \multicolumn{1}{c}{$\begin{array}{c}\text { INSTITUTOS } \\
\text { PROFESIONALES }\end{array}$} & $\begin{array}{c}\text { CENTROS DE } \\
\text { FORMACIÓN TÉCNICA }\end{array}$ \\
\hline A & De Chile & & DuocUC & IP y CFT DuocUC \\
& Pontificia Univ. Católica & & INACAP & IP CFT INACAP \\
de Chile & & & \\
& De Concepción & & & \\
\hline B & Pontificia Univ. Católica & Adolfo Ibáñez & Instituto de Estudios & IP y CFT Santo Tomás \\
& de Valparaíso & Alberto Hurtado & Bancarios Guillermo & Instituto Guillermo \\
& Técnica Federico & & Subercaseaux & Subercaseaux \\
& Santa María & & La Araucana & La Araucana \\
& De Santiago de Chile & & Santo Tomás & Virginio Gómez \\
& Austral de Chile & & Virginio Gómez & \\
& Católica del Norte & & & \\
De Valparaíso & & & \\
De La Frontera & & & \\
De Talca & & & \\
\hline C & & & \\
De Antofagasta & Católica Cardenal & & \\
De La Serena & Raúl Silva Henríquez & & \\
Del Bío-Bío & Del Pacífico & & \\
De Magallanes & Diego Portales & & \\
& & &
\end{tabular}

i Fondo Nacional de Desarrollo Científico y Tecnológico.

ii Institute for Scientific Information.

iii Scientific Electronic Library Online. 


\begin{tabular}{|c|c|c|}
\hline & $\begin{array}{l}\text { De Tarapacá } \\
\text { Arturo Prat } \\
\text { De Playa Ancha de } \\
\text { Ciencias de la Educación } \\
\text { De Los Lagos }\end{array}$ & $\begin{array}{l}\text { Mayor } \\
\text { Nacional Andrés Bello }\end{array}$ \\
\hline $\mathrm{D}$ & $\begin{array}{l}\text { De Atacama } \\
\text { Metropolitana de } \\
\text { Ciencias de la Educación } \\
\text { Tecnológica Metropolitana } \\
\text { Católica del Maule } \\
\text { Católica de la Santísima } \\
\text { Concepción } \\
\text { Católica de Temuco }\end{array}$ & $\begin{array}{l}\text { Academia de } \\
\text { Humanismo Cristiano } \\
\text { Central de Chile } \\
\text { De Viña del Mar } \\
\text { Iberoamericana } \\
\text { de Ciencias y } \\
\text { Tecnología } \\
\text { Santo Tomás } \\
\text { UNIACC }\end{array}$ \\
\hline
\end{tabular}

Una vez establecidos los grupos, el arancel referencial se aplica según tramo, calculado sobre la base de un promedio de aranceles de los años 1998 a 2000 de aquella universidad que posea los mejores indicadores de su grupo. En cada grupo de instituciones, para una carrera particular se utilizan dos criterios: rigen el arancel de aquella universidad que haya sido acreditada por más años y el arancel más bajo del grupo, que no puede ser menor al arancel promedio del grupo para cada carrera.

El MINEDUC efectuó algunos ajustes a los aranceles de referencia vigentes hasta 2005, asociados a aquellas carreras creadas después de 2000. Así, sus aranceles de referencia son producto de la imputación del arancel de referencia del sistema, lo que explica que en algunas de estas carreras los aranceles referenciales tengan coberturas particularmente altas o bajas.

Sobre la base de los criterios descritos, el Ministerio fijó y publicó el valor de referencia de los aranceles para el año 2006 de las carreras de todas las instituciones que pueden recibir estudiantes con créditos.

En términos de la recopilación de los valores de referencia para efectos de este estudio, los datos fueron obtenidos de las listas publicadas por el Ministerio de Educación sobre los aranceles de 
referencia para distintas carreras de universidades, institutos profesionales y centros de formación técnica. Dichas listas, con sus respectivos aranceles de referencia, fueron descargadas del sitio web www.mineduc.cl, el lunes 17 de abril de 2006, esto es, el mismo día en que se dio inicio a la etapa de recopilación de información, y constituyeron la base para construir la lista de valores reales 2006 con la que fue comparado.

La lista del MINEDUC está distribuida en cuatro bases de datos, esto es, los valores de las carreras de las universidades del CRUCH, de las universidades privadas, de los institutos profesionales (IP) y de los centros de formación técnica (CFT). Cabe aclarar que se trabajó con las bases de datos separadamente, debido a que la unidad de análisis era diferente en unas y en otra $^{\text {iv }}$.

De estas listas se eliminaron aquellas carreras que, según la fuente de las instituciones, no existían y las que se encontraban repetidas. También se suprimieron los casos repetidos para cada base, según los siguientes criterios: a) para los CFT, los IP y las universidades privadas, la unidad de análisis es una carrera impartida en una sede en particular; b) para las universidades del $\mathrm{CRUCH}$, cada caso correspondió al código que el Ministerio asignó a cada carrera en cada sede para el proceso de postulación a las universidades chilenas.

\section{Acerca de los aranceles reales}

Al hablar de arancel real nos referimos al monto que cada alumno debe pagar anualmente por cursar sus estudios superiores,

iv En el conjunto de universidades del CRUCH se utilizó como unidad de análisis cada carrera, correspondiente a un código que le asigna el Ministerio de Educación para individualizar los programas en el contexto del proceso de postulación a las universidades. Las universidades privadas, IP y CFT no fueron publicadas con códigos por el Ministerio, por lo que la unidad de análisis es una carrera impartida por una institución en una sede determinada. 
excluyendo la cuota de matrícula que las instituciones cobran al comienzo de cada año o de cada semestre, y situaciones como descuentos en los valores o becas parciales o totales. Además, el arancel de interés para este estudio es el valor real correspondiente al primer semestre de 2006 .

Para obtener la información, las listas de los valores de los aranceles reales para cada carrera de cada institución fueron completadas a través de consulta telefónica directa con las oficinas de admisión de las instituciones, o bien mediante la información ofrecida en sus sitios web sobre aranceles, previa consulta sobre la actualización de los datos en su página electrónica.

En el caso de las universidades del CRUCH, se utilizó la información sobre el proceso de admisión que se publica anualmente a través del diario El Mercurio y que contempla, entre otros aspectos, los aranceles cobrados por estas instituciones en cada uno de sus programas académicos. Ello, previa consulta al CRUCH sobre la validez de dicha fuente. La información sobre el proceso de admisión correspondiente a 2006 fue publicada en la edición de ese diario del lunes 19 de diciembre de 2005.

En el grupo de las universidades privadas, sólo en dos casos no fue posible obtener los datos a la fecha de recopilación de información, por lo que se utilizó la última entregada al Consejo Superior de Educación (CSE). Cabe precisar que, en los casos en que los aranceles aparecen informados en unidades de fomento (UF), se utilizó para la conversión el valor de la UF del 25 de abril de 2006, fecha en que se recabó la mayoría de la información.

\section{Principales hallazgos}

El arancel de referencia que se asignó a las carreras del Consejo de Rectores (CRUCH), según las variables ya mencionadas, define el monto máximo de Crédito Solidario que un estudiante podría 
recibir en caso de obtener un 100\% de este tipo de beneficio. De modo similar, también sirve como referencia para la entrega del Crédito con Aval del Estado, disponible para matriculados en instituciones de educación superior que se hayan acreditado ante la Comisión Nacional de Acreditación de Pregrado (CNAP). En esta situación se encuentran seis CFT, seis IP, 13 universidades privadas y 22 universidades del $\mathrm{CRUCH}^{\mathrm{v}}$.

Los hallazgos de este estudio se presentarán por separado según se trate de CFT, IP, universidades privadas o universidades del $\mathrm{CRUCH}$, sin perjuicio de que, al inicio, también se incluyen algunos gráficos comparativos que revelen la disparidad de escenarios. Se han explorado las diferencias en pesos y la diferencia porcentual entre el arancel referencial y el real para el conjunto de las carreras, valiéndose de descriptores como:

- La distribución de las diferencias porcentuales con criterio de un $10 \%$.

- La distribución de las diferencias porcentuales con criterio de un $20 \%$.

- La diferencia promedio entre arancel real y de referencia.

- La máxima diferencia negativa (arancel real > de referencia).

- La máxima diferencia positiva (arancel real < de referencia).

Aunque se ha hecho un esfuerzo por explotar al máximo todas las bases, debido al número de instituciones y de carreras que contiene, la categoría CRUCH fue la más susceptible de indagar en detalle para descubrir cómo se expresan las diferencias absolutas y relativas entre el monto que establece el Estado y el que fijan las entidades autónomas, dependiendo de la institución y área del conocimiento.

v Tres universidades del CRUCH no obtuvieron la acreditación pero sus alumnos siguen siendo elegibles para efectos del Crédito Solidario. 


\section{Comparación inicial entre grupos de instituciones}

En términos generales, los gráficos siguientes muestran qué porcentaje de carreras tiene un precio por sobre, igual o menor al arancel de referencia. Se utilizaron dos criterios, de 10 y 20\%, para agrupar las carreras en virtud del déficit o superávit que sus precios mostraban respecto del arancel que sirve de parámetro para la asignación de ayudas estudiantiles.

La distribución que resulta de la aplicación de un criterio de $10 \%$ de diferencia entre el valor real y lo que estipula el valor referencial indica que prácticamente el $80 \%$ de las carreras impartidas por universidades integrantes del CRUCH y el $77 \%$ de los programas impartidos en universidades privadas cobra un $10 \%$ más caro que el monto máximo que el Estado se compromete a cubrir por la vía de créditos a aquellos estudiantes elegibles. Al contrario, IP y CFT tienen muy pocas de sus carreras en esta situación, por lo que sus precios, en general, no difieren sustantivamente del parámetro arancelario que fija el Estado.

Gráfico 1. Comparación con criterio 10\% de diferencia.

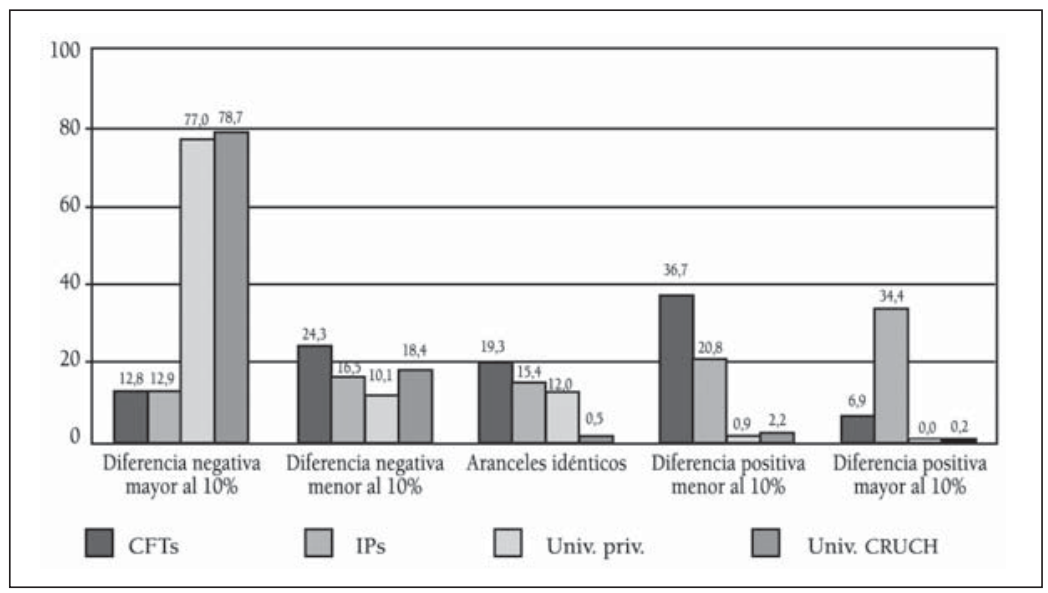

Cuando se ocupa un criterio del 20\% de diferencia entre aranceles institucionales y los fijados desde el MINEDUC para 
agrupar a las carreras, alrededor de un 30\% de los programas dependientes de universidades del CRUCH cobra más de un 20\% por sobre el arancel de referencia. Son las universidades privadas las que concentran la mayor parte de carreras, cuyos aranceles de referencia están un $20 \%$ por debajo del valor establecido por cada institución. Salvo casos muy excepcionales, las carreras de IP y CFT no muestran brechas tan marcadas.

Gráfico 2. Comparación con criterio 20\% de diferencia.

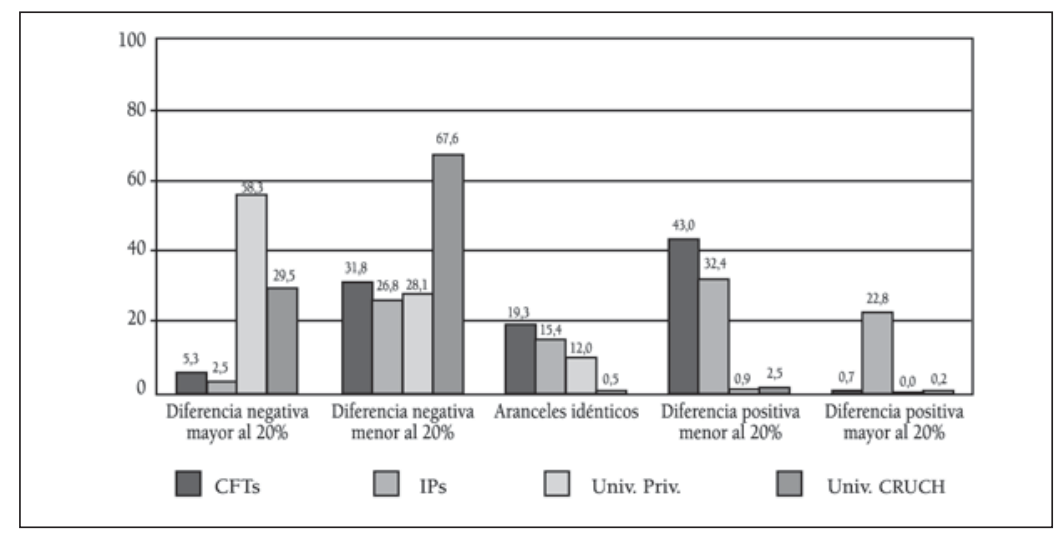

\section{Centros de formación técnica}

Los datos recogidos muestran que, como ya se anunciara, las instituciones acreditadas de este tipo no presentan grandes diferencias entre el arancel real y el de referencia.

Diferencia en pesos (arancel referencia - arancel real)

\begin{tabular}{lrl}
\hline Diferencia promedio & $-\$ 27.270$ & \\
Máxima diferencia negativa & $-\$ 844.500$ & $\begin{array}{l}\text { Gastronomía Internacional (en INACAP) } \\
\text { Máxima diferencia positiva }\end{array}$ \\
& $\$ 160.000$ & $\begin{array}{l}\text { Administración y Soporte de Redes } \\
\text { Computacionales / Analista Programador } \\
\text { (ambas DuocUC-Concepción) }\end{array}$
\end{tabular}

Diferencia porcentual (arancel referencia - arancel real)

Diferencia promedio $\quad-1,53 \%$

Máxima diferencia negativa $\quad-49,52 \%$

Máxima diferencia positiva $\quad 21,33 \%$ 
De un total de 305 carreras, todos aquellos casos en que la diferencia es de más de $\$ 300.000$ anuales corresponden a INACAP en alguna de sus sedes de Santiago. Este CFT, al igual que DuocUC, fueron clasificados en la categoría "A" por el Ministerio de Educación, no obstante, es evidente que este último presenta cobros que están en mayor sintonía con los aranceles de referencia.

En rigor, existe alta variabilidad entre los aranceles de una misma carrera dependiendo de la institución y sede donde se estudia. Un ejemplo de ello son los programas de administración que hemos seleccionado a continuación, los que ostentan hasta un 91\% de diferencia entre el CFT con el arancel más caro y aquel con el arancel más económico. Eso sí, a pesar de la distancia entre los valores extremos, se debe poner atención en que sólo los dos primeros programas de la tabla 1 sobrepasan sustantivamente el monto referencial que pone los límites al posible préstamo por la vía del Crédito con Aval del Estado.

Tabla 1. Aranceles de programas de administración.

\begin{tabular}{|c|c|c|c|c|}
\hline INSTITUCIÓN & PROGRAMA & ARANCEL REAL & $\begin{array}{c}\text { ARANCEL } \\
\text { DE REFERENCIA }\end{array}$ & DIFERENCIA \\
\hline $\begin{array}{l}\text { CFT/IP Inacap } \\
\text { (Antofagasta) } \\
\end{array}$ & Administración de Empresas & $\$ 1.031 .500$ & $\$ 827.500$ & $-\$ 204.000$ \\
\hline $\begin{array}{l}\text { CFT/IP Inacap } \\
\text { (Santiago) }\end{array}$ & Administración de Empresas & 920.000 & $\$ 827.500$ & $-\$ 92.500$ \\
\hline $\begin{array}{l}\text { Virginio Gómez } \\
\text { (Concepción) }\end{array}$ & $\begin{array}{l}\text { Técnico de Nivel Superior } \\
\text { en Administración }\end{array}$ & $\$ 718.000$ & $\$ 686.000$ & $-\$ 32.000$ \\
\hline $\begin{array}{l}\text { CFT/IP DuocUC } \\
\text { (Plaza Vespucio) }\end{array}$ & $\begin{array}{l}\text { Administración de Empresas } \\
\text { Mención Marketing }\end{array}$ & 830.000 & $\$ 810.000$ & $-\$ 20.000$ \\
\hline $\begin{array}{l}\text { Virginio Gómez } \\
\text { (Los Ángeles) }\end{array}$ & $\begin{array}{l}\text { Técnico de Nivel Superior } \\
\text { en Administración }\end{array}$ & $\$ \quad 678.000$ & $\$ 676.000$ & $-\$ 2.000$ \\
\hline $\begin{array}{l}\text { CFT/IP DuocUC } \\
\text { (Alonso Ovalle) }\end{array}$ & $\begin{array}{l}\text { Administración de Empresas } \\
\text { Mención Logística }\end{array}$ & 810.000 & $\$ 810.000$ & $\$$ \\
\hline $\begin{array}{l}\text { CFT/IP DuocUC } \\
\text { (Alonso Ovalle) }\end{array}$ & $\begin{array}{l}\text { Administración de Empresas } \\
\text { Mención Marketing }\end{array}$ & 810.000 & $\$ 810.000$ & $\$$ \\
\hline $\begin{array}{l}\text { La Araucana } \\
\text { (Curicó) }\end{array}$ & Administración de Empresas & 540.000 & $\$ 540.000$ & $\$$ \\
\hline $\begin{array}{l}\text { CFT/IP DuocUC } \\
\text { (Plaza Oeste) }\end{array}$ & $\begin{array}{l}\text { Administración de Empresas } \\
\text { Mención Marketing }\end{array}$ & $\$ 790.000$ & $\$ 810.000$ & $\$ 20.000$ \\
\hline $\begin{array}{l}\text { CFT/IP DuocUC } \\
\text { (Viña del Mar) }\end{array}$ & $\begin{array}{l}\text { Administración de Empresas } \\
\text { Mención Marketing }\end{array}$ & $\$ 770.000$ & $\$ 810.000$ & $\$ 40.000$ \\
\hline
\end{tabular}


Es clave tener presente en estos análisis comparativos entre carreras que las instituciones que las imparten pertenecen a diferentes tramos de los definidos por el MINEDUC, por lo tanto, al contrastar las brechas se debe considerar que los aranceles de referencia de las instituciones del grupo A son mayores que las de los otros grupos. Por lo tanto, la diferencia absoluta entre el arancel real y el de referencia debe ser examinada a la luz del grupo al que pertenece cada institución.

\section{Institutos profesionales}

Tan sólo siete carreras tienen diferencias de más de \$300.000 al año, todas impartidas por DuocUC o INACAP y todas en Apoquindo. $\mathrm{Al}$ igual que los CFTs respectivos, ambas instituciones se incluyen en la categoría "A" de la clasificación ministerial.

\begin{tabular}{|c|c|c|}
\hline \multicolumn{3}{|c|}{ Diferencia en pesos (arancel referencia - arancel real) } \\
\hline Diferencia promedio & $\$ 21.442$ & \\
\hline Máxima diferencia negativa & $-\$ 575.250$ & $\begin{array}{l}\text { Ingeniería de Ejecución en Sonido } \\
\text { (DuocUC-Apoquindo) }\end{array}$ \\
\hline Máxima diferencia positiva & $\$ 413.915$ & $\begin{array}{l}\text { Nutrición y Alimentación Institucional } \\
\text { (INACAP-La Serena) }\end{array}$ \\
\hline \multicolumn{3}{|c|}{ Diferencia porcentual (arancel referencia - arancel real en \% del arancel real) } \\
\hline Diferencia promedio & $3,48 \%$ & \\
\hline Máxima diferencia negativa & $-33,84 \%$ & \\
\hline Máxima diferencia positiva & $57,30 \%$ & \\
\hline
\end{tabular}

Por otro lado, a diferencia de los CFTs, entre los IP hay una mayor proporción de carreras sin diferencia entre aranceles reales y de referencia o cuya diferencia es positiva. De 349 casos, en 233 el precio es menor que el monto referencial fijado por el Estado.

Antes de continuar el análisis de la distancia entre precios reales y montos referenciales, es necesario hacer un paréntesis para abordar un aspecto que se ha vuelto especialmente notorio en los últimos años, esto es, la variación de precios dependiendo de la sede, incluso dentro de una misma ciudad. La importancia de exponer 
estos datos radica en la necesidad de indagar si la ubicación geográfica se asocia o no con la fijación de aranceles de referencia distintos.

Aunque esta arista en la determinación de cobros es digna de análisis en el conjunto de instituciones de educación superior que operan en más de una sede, dos institutos profesionales representan casos paradigmáticos de expansión territorial consolidada, por lo que resultan interesantes de explorar desde la perspectiva de este estudio. La tabla 2 contiene un ranking de las carreras que, siendo impartidas por la misma institución, cobran aranceles muy distintos según la región o comuna donde se desarrollen los programas.

Tabla 2. Ranking de diferencias de arancel real entre carreras impartidas en más de tres sedes de la misma institución

\begin{tabular}{|c|c|c|c|c|c|}
\hline $\begin{array}{l}\text { INSTITUTO } \\
\text { PROFESIONAL }\end{array}$ & PROGRAMA & $\begin{array}{l}\text { ARANCEL } \\
\text { MIN }\end{array}$ & $\begin{array}{l}\text { ARANCEL } \\
\text { MAX }\end{array}$ & DIF \$ & DIF \% \\
\hline Inacap & $\begin{array}{l}\text { Administración Hotelera } \\
\text { Internacional }\end{array}$ & 907.500 & $\$ 1.705 .500$ & $\$ 798.000$ & $87,9 \%$ \\
\hline Inacap & $\begin{array}{l}\text { Administración de Empresas } \\
\text { Turísticas }\end{array}$ & 919.500 & $\$ 1.705 .500$ & $\$ 786.000$ & $85,5 \%$ \\
\hline Inacap & Diseño de Vestuario & $\$ 871.000$ & $\$ 1.467 .500$ & $\$ 596.500$ & $68,5 \%$ \\
\hline Inacap & $\begin{array}{l}\text { Administración Gastronómica } \\
\text { Internacional }\end{array}$ & $\$ 1.016 .500$ & $\$ 1.705 .500$ & $\$ 689.000$ & $67,8 \%$ \\
\hline Inacap & Diseño Gráfico Profesional & $\$ 876.000$ & $\$ 1.467 .500$ & $\$ 591.500$ & $67,5 \%$ \\
\hline Inacap & Ingeniería Agrícola & $\$ 907.500$ & $\$ 1.492 .500$ & $\$ 585.000$ & $64,5 \%$ \\
\hline Inacap & $\begin{array}{l}\text { Nutrición y Alimentación } \\
\text { Institucional }\end{array}$ & $\$ 850.000$ & $\$ 1.323 .000$ & $\$ 473.000$ & $55,6 \%$ \\
\hline DuocUC & Publicidad & $\$ 1.030 .000$ & $\$ 1.600 .000$ & $\$ 570.000$ & $55,3 \%$ \\
\hline DuocUC & Diseño Gráfico & $\$ 1.020 .000$ & $\$ 1.480 .000$ & $\$ 460.000$ & $45,1 \%$ \\
\hline DuocUC & $\begin{array}{l}\text { Relaciones Públicas } \\
\text { Mención Marketing }\end{array}$ & $\$ 1.020 .000$ & $\$ 1.480 .000$ & $\$ 460.000$ & $45,1 \%$ \\
\hline Inacap & Publicidad & $\$ 1.016 .500$ & $\$ 1.467 .500$ & $\$ 451.000$ & $44,4 \%$ \\
\hline Inacap & Contador Auditor & $\$ 846.000$ & $\$ 1.213 .000$ & $\$ 367.000$ & $43,4 \%$ \\
\hline DuocUC & Comunicación Audiovisual & $\$ 1.220 .000$ & $\$ 1.740 .000$ & $\$ 520.000$ & $42,6 \%$ \\
\hline Inacap & Comunicación Empresarial & 950.000 & $\$ 1.337 .000$ & $\$ 387.000$ & $40,7 \%$ \\
\hline Inacap & $\begin{array}{l}\text { Ingeniería Maquinaria y } \\
\text { Vehículos Automotrices }\end{array}$ & 807.500 & $\$ 1.100 .000$ & $\$ 292.500$ & $36,2 \%$ \\
\hline Inacap & $\begin{array}{l}\text { Ingeniería en Negocios } \\
\text { Internacionales }\end{array}$ & 914.500 & $\$ 1.213 .000$ & $\$ 298.500$ & $32,6 \%$ \\
\hline DuocUC & $\begin{array}{l}\text { Ingeniería Ejecución en } \\
\text { Administración Turística }\end{array}$ & $\$ 1.020 .000$ & $\$ 1.350 .000$ & $\$ 330.000$ & $32,4 \%$ \\
\hline
\end{tabular}


Pudiera ser que los datos reflejen modelos más o menos descentralizados de gestión, con el fin de hacer frente a escenarios de mercado dinámicos y captar públicos diversos. Aún así, cabe preguntarse sobre las bases en que se fundan los contrastes y sobre las implicancias para la calidad desde el punto de vista de los usuarios que optan por una u otra sede, y desde la perspectiva del apoyo estatal indirecto del que se benefician estos planteles mediante el Crédito con Aval del Estado.

Estas brechas de precios para un mismo programa según sede impactan el análisis que pueda realizarse en torno al arancel de referencia, en tanto multiplican los casos que muestran diferencias entre el arancel real y el referencial. Ello agrega, pues, una nueva complejidad que ya no está dada sólo por la distancia de valores entre instituciones para una misma carrera, sino también por la diferencia según la sede en que se dicte. Se revisará a continuación la variabilidad de precios entre instituciones y sedes para un mismo tipo de programa, incorporando la información sobre aranceles de referencia.

Tabla 3. Aranceles de programas de auditoría/contador auditor.

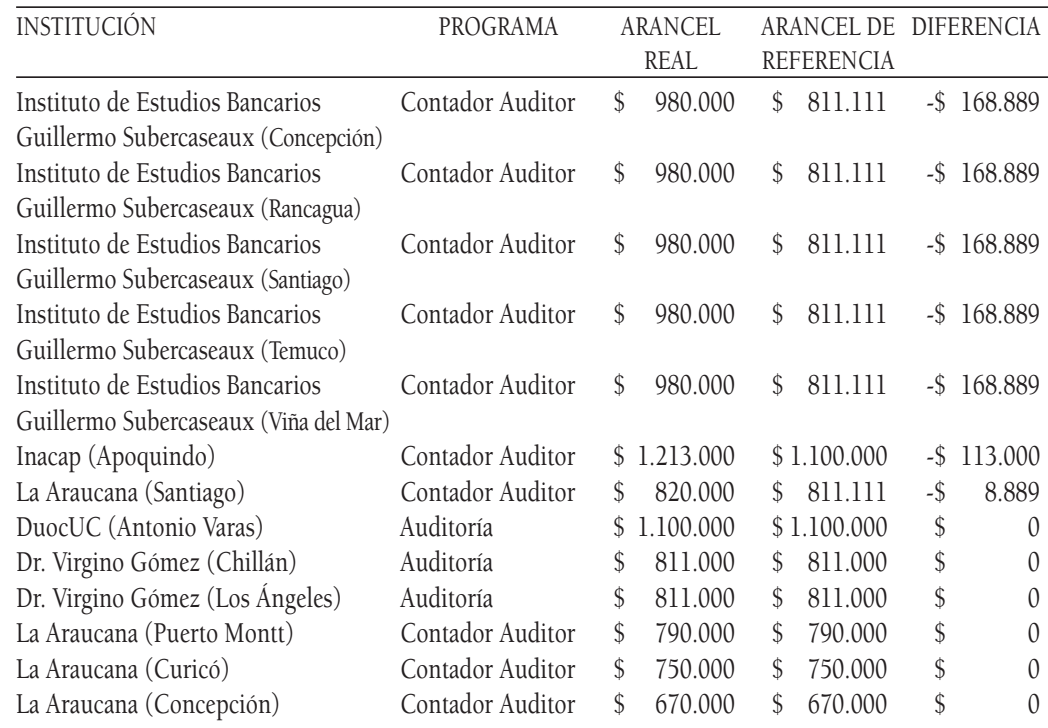




\begin{tabular}{llllll} 
DuocUC (Plaza Oeste) & Auditoría & $\$ 1.060 .000$ & $\$ 1.100 .000$ & $\$ 40.000$ \\
DuocUC (Plaza Vespucio) & Auditoría & $\$ 1.060 .000$ & $\$ 1.100 .000$ & $\$ 40.000$ \\
DuocUC (Viña del Mar) & Auditoría & $\$ 1.050 .000$ & $\$ 1.100 .000$ & $\$ 50.000$ \\
Inacap (Santiago Centro) & Contador Auditor & $\$ 1.040 .500$ & $\$ 1.100 .000$ & $\$ 59.500$ \\
Inacap (Rancagua) & Contador Auditor & $\$ 1.016 .500$ & $\$ 1.100 .000$ & $\$ 83.500$ \\
Inacap (Maipú) & Contador Auditor & $\$ 1.007 .500$ & $\$ 1.100 .000$ & $\$ 92.500$ \\
Inacap (Iquique) & Contador Auditor & $\$ 970.000$ & $\$ 1.100 .000$ & $\$ 130.000$ \\
Inacap (Coyhaique) & Contador Auditor & $\$ 960.000$ & $\$ 1.100 .000$ & $\$ 140.000$ \\
Inacap (Valparaíso) & Contador Auditor & $\$ 953.500$ & $\$ 1.100 .000$ & $\$ 146.500$ \\
Inacap (Curicó) & Contador Auditor & $\$ 928.500$ & $\$ 1.100 .000$ & $\$ 171.500$ \\
Inacap (Talca) & Contador Auditor & $\$ 928.500$ & $\$ 1.100 .000$ & $\$ 171.500$ \\
Inacap (Chillán) & Contador Auditor & $\$ 915.000$ & $\$ 1.100 .000$ & $\$ 185.000$ \\
Inacap (Calama) & Contador Auditor & $\$ 912.500$ & $\$ 1.100 .000$ & $\$ 187.500$ \\
Inacap (La Serena) & Contador Auditor & $\$ 907.500$ & $\$ 1.100 .000$ & $\$ 192.500$ \\
Inacap(Copiapó) & Contador Auditor & $\$ 892.000$ & $\$ 1.100 .000$ & $\$ 208.000$ \\
Inacap (Osorno) & Contador Auditor & $\$ 876.000$ & $\$ 1.100 .000$ & $\$ 224.000$ \\
Inacap (Valdivia) & Contador Auditor & $\$ 851.000$ & $\$ 1.100 .000$ & $\$ 249.000$ \\
Inacap (Concepción) & Contador Auditor & $\$ 846.000$ & $\$ 1.100 .000$ & $\$ 254.000$ \\
\hline
\end{tabular}

Tal como se hiciera con los CFT, el programa que sirve de ejemplo se ofrece en la mayoría de los institutos profesionales estudiados (tabla 3). Llama la atención que, no obstante que las diferencias en el arancel real llegan hasta el $81 \%$, los aranceles de referencia correspondientes no distan demasiado de los reales en cada programa, por lo que no se puede hablar de déficits sustantivos que los planteles debieran cubrir ante la eventual asignación de Créditos con Aval del Estado a sus estudiantes. Así, los montos máximos cubiertos por este tipo de crédito estarían determinados por la clasificación en la que cada institución cae, al margen de la ciudad o comuna donde se imparte el programa. Salvo muy pocas excepciones (programas impartidos en el sector oriente de Santiago), se observa un fuerte alineamiento de los precios anuales reales con los aranceles de referencia, incluso en aquellas carreras con alta dispersión de precios en el mercado.

\section{Universidades privadas}

El total de carreras que compone la base de universidades privadas generada para llevar a cabo este estudio es de 543. Claramente, las cifras a continuación revelan diferencias de mayor envergadura 
entre aranceles reales y de referencia en comparación con las que exhiben los IP y CFT. Desde ya, basta ver los valores máximos y mínimos de diferencia en este grupo.

\begin{tabular}{|c|c|c|}
\hline \multicolumn{3}{|c|}{ Diferencia en pesos (arancel referencia - arancel real) } \\
\hline Diferencia promedio & $-\$ \quad 596.845$ & \\
\hline Máxima diferencia negativa & $-\$ 2.674 .750$ & $\begin{array}{l}\text { Traducción e Interpretariado } \\
\text { (UNIACC) }\end{array}$ \\
\hline Máxima diferencia positiva & 113.344 & $\begin{array}{l}\text { Ingeniería Comercial (V) } \\
\text { (Universidad Iberoamericana de } \\
\text { Ciencia y Tecnología) }\end{array}$ \\
\hline \multicolumn{3}{|c|}{ Diferencia porcentual (arancel referencia - arancel real en \% del arancel real) } \\
\hline Diferencia promedio & $-25,53 \%$ & \\
\hline Máxima diferencia negativa & $-70,28 \%$ & \\
\hline Máxima diferencia positiva & $8,06 \%$ & \\
\hline
\end{tabular}

Una revisión rigurosa exige poner atención al comportamiento de varias carreras de una institución y no sólo a los casos donde se manifiestan diferencias extremas. Al ordenar la base de carreras según las diferencias en pesos, hay una universidad cuyos programas ocupan los primeros puestos del ranking. Las 20 carreras que acentuadamente cobran por encima del precio referencial pertenecen a la UNIACC y las carreras con alguna diferencia a favor del arancel real corresponden a sólo cinco programas en el área de administración de distintas universidades. Las carreras que les siguen son aquellas que no muestran diferencias con el arancel referencial y pertenecen, en su mayoría, a la Universidad Santo Tomás en sus diversas sedes. Casi todas ellas son impartidas en ciudades distintas a Santiago. Esto lleva a pensar que el precio es una característica institucional y, por lo tanto, también lo será la brecha con el arancel de referencia, aun cuando las dos instituciones aludidas fueron clasificadas en el mismo tramo arancelario por el MINEDUC (D).

Las dos únicas universidades clasificadas en la categoría B por el MINEDUC fueron Adolfo Ibáñez y Alberto Hurtado; sin embargo, mientras las carreras de la primera exhiben diferencias negativas considerables con los aranceles de referencia anual (-\$1.125.416), las 
de la segunda tienen un promedio de diferencia menor (-\$490.948) que el del conjunto de programas impartidos por universidades privadas (-\$596.845).

Siguiendo con el examen comparativo más específico, las tablas 5,6 y 7 informan sobre los aranceles reales y de referencia para tres carreras universitarias usualmente denominadas "tradicionales": Ingeniería Comercial, Derecho y Psicología.

Tabla 4. Diferencias absolutas y porcentuales entre arancel real y de referencia.

\begin{tabular}{|c|c|c|c|}
\hline UNIVERSIDAD & DIF. MEDIA \$ & DIF. MEDIA \% & Programas \\
\hline UNIACC & $-\$ 2.358 .454$ & $-62,0$ & 27 \\
\hline Adolfo Ibáñez & $-\$ 1.125 .415$ & $-41,5$ & 14 \\
\hline Diego Portales & -\$ 985.219 & $-39,5$ & 33 \\
\hline Nacional Andrés Bello & 828.867 & $-35,5$ & 83 \\
\hline Mayor & 782.544 & $-33,5$ & 65 \\
\hline Central de Chile & 618.380 & $-30,7$ & 47 \\
\hline Alberto Hurtado & 428.882 & $-23,9$ & 17 \\
\hline Del Pacífico & 414.650 & $-18,0$ & 32 \\
\hline De Viña del Mar & 379.202 & $-22,5$ & 30 \\
\hline Iberoamericana de Ciencia y Tecnología & 309.058 & $-18,3$ & 31 \\
\hline Católica Cardenal Raúl Silva Henríquez & 262.084 & $-18,3$ & 17 \\
\hline Academia de Humanismo Cristiano & 170.865 & $-11,6$ & 21 \\
\hline Santo Tomás & 152.425 & $-9,3$ & 143 \\
\hline
\end{tabular}

Nuevamente, a juzgar por lo disímil de los precios comparados dentro de una misma carrera y la proporción del arancel que, eventualmente, se puede pagar valiéndose del Crédito con Aval del Estado, queda de manifiesto que las universidades se plantean en posiciones muy dispares respecto de este nuevo instrumento de ayuda estudiantil, en función, por ejemplo, del perfil socioeconómico del estudiante que reciben y que aspiran a recibir. Es posible suponer que las instituciones más beneficiadas con esta oportunidad serán aquellas con cobros anuales inferiores al promedio del mercado, en el entendido que pretendan captar estudiantes potencialmente elegibles para crédito. En ese caso estarían las universidades Academia de Humanismo Cristiano, Cardenal Raúl Silva Henríquez, Iberoamericana de Ciencia y Tecnología y Santo Tomás, aunque tampoco se puede descartar que las más costosas capten estudiantes 
que no solían atraer, al margen de las altas diferencias con el arancel referencial.

Tabla 5. Aranceles de programas de ingeniería comercial.

\begin{tabular}{lcccr}
\hline UNIVERSIDAD & ARANCEL REAL & $\begin{array}{c}\text { ARANCEL } \\
\text { REFERENCIA }\end{array}$ & DIFERENCIA \\
\hline Diego Portales & & $\$ 2.701 .467$ & $\$ 1.530 .533$ & $-\$ 1.170 .934$ \\
Adolfo Ibáñez (V)* (Santiago) & $\$ 2.875 .978$ & $\$ 1.755 .877$ & $-\$ 1.120 .101$ \\
Central de Chile & $\$ 2.598 .000$ & $\$ 1.520 .344$ & $-\$ 1.077 .656$ \\
Nacional Andrés Bello (Santiago) & $\$ 2.570 .000$ & $\$ 1.530 .533$ & $-\$ 1.039 .467$ \\
Nacional Andrés Bello (Viña Del Mar) & $\$ 2.569 .800$ & $\$ 1.530 .533$ & $-\$ 1.039 .267$ \\
Mayor (Santiago) & $\$ 2.490 .000$ & $\$ 1.530 .533$ & $-\$$ & 959.467 \\
Adolfo Ibánez (V) (Viña Del Mar) & $\$ 2.516 .480$ & $\$ 1.755 .877$ & $-\$$ & 760.603 \\
De Viña del Mar & $\$ 1.984 .000$ & $\$ 1.520 .344$ & $-\$$ & 463.656 \\
Mayor (V) (Santiago) & $\$ 1.965 .000$ & $\$ 1.530 .533$ & $-\$$ & 434.467 \\
Alberto Hurtado & $\$ 2.181 .480$ & $\$ 1.755 .877$ & $-\$$ & 425.603 \\
Mayor (Temuco) & $\$ 1.945 .000$ & $\$ 1.530 .533$ & $-\$$ & 414.467 \\
Del Pacífico & $\$ 1.880 .000$ & $\$ 1.530 .533$ & $-\$$ & 349.467 \\
Santo Tomás (Santiago) & $\$ 1.800 .000$ & $\$ 1.520 .344$ & $-\$$ & 279.656 \\
Del Pacífico (V) & $\$ 1.690 .000$ & $\$ 1.530 .533$ & $-\$$ & 159.467 \\
Iberoamericana de Ciencia y Tecnología & $\$ 1.578 .000$ & $\$ 1.520 .344$ & $-\$$ & 57.656 \\
Santo Tomás (V) (Santiago) & $\$ 1.500 .000$ & $\$ 1.500 .000$ & $\$$ & 0 \\
Santo Tomás (Los Ángeles) & $\$ 1.405 .000$ & $\$ 1.405 .000$ & $\$$ & 0 \\
Santo Tomás (V) (Antofagasta) & $\$ 1.345 .000$ & $\$ 1.345 .000$ & $\$$ & 0 \\
Santo Tomás (Puerto Montt) & $\$ 1.215 .000$ & $\$ 1.215 .000$ & $\$$ & 0 \\
Católica Cardenal Raúl Silva Henríquez & $\$ 1.367 .000$ & $\$ 1.445 .000$ & $\$$ & 78.000 \\
Iberoamericana de Ciencia y Tecnología (V) & $\$ 1.407 .000$ & $\$ 1.520 .344$ & $\$$ & 113.344 \\
\hline
\end{tabular}

* Vespertino (V)

Como se aprecia en las tablas 5, 6 y 7, en la mayoría de los casos el arancel real excede al referencial en un monto considerable. Las instituciones que exhiben las mayores diferencias son las universidades UNIACC, Adolfo Ibáñez, Diego Portales y Nacional Andrés Bello. Sus precios sobrepasan en alrededor de un millón de pesos el valor referencial.

Tabla 6. Aranceles de programas de Derecho.

\begin{tabular}{lccc}
\hline UNIVERSIDAD & ARANCEL REAL & $\begin{array}{c}\text { ARANCEL } \\
\text { REFERENCIA }\end{array}$ & DIFERENCIA \\
\hline Adolfo Ibáñez (Santiago) & $\$ 2.875 .978$ & $\$ 1.653 .996$ & $-\$ 1.221 .982$ \\
Central de Chile (Santiago) & $\$ 2.658 .000$ & $\$ 1.520 .344$ & $-\$ 1.137 .656$ \\
Diego Portales & $\$ 2.722 .109$ & $\$ 1.653 .996$ & $-\$ 1.068 .113$
\end{tabular}




\begin{tabular}{llllrl} 
Nacional Andrés Bello (Santiago) & $\$ 2.570 .000$ & $\$ 1.653 .996$ & $-\$$ & 916.004 \\
Nacional Andrés Bello (Viña del Mar) & $\$ 2.570 .000$ & $\$ 1.653 .996$ & $-\$$ & 916.004 \\
Adolfo Ibáñez (Viña del Mar) & $\$ 2.516 .480$ & $\$ 1.653 .996$ & $-\$$ & 862.484 \\
Alberto Hurtado & $\$ 2.247 .200$ & $\$ 1.653 .996$ & $-\$$ & 593.204 \\
Central de Chile (V)* (Santiago) & $\$ 2.064 .000$ & $\$ 1.520 .344$ & $-\$$ & 543.656 \\
Santo Tomás (Santiago) & $\$ 2.000 .000$ & $\$ 1.520 .344$ & $-\$$ & 479.656 \\
Mayor & $\$ 1.945 .000$ & $\$ 1.653 .996$ & $-\$$ & 291.004 \\
De Viña del Mar & $\$ 1.900 .000$ & $\$ 1.520 .344$ & $\$$ & 379.656 \\
Central de Chile (Antofagasta) & $\$ 1.800 .000$ & $\$ 1.520 .344$ & $-\$$ & 279.656 \\
Central de Chile (V) (Antofagasta) & $\$ 1.800 .000$ & $\$ 1.520 .344$ & $-\$$ & 279.656 \\
Central de Chile (La Serena) & $\$ 1.734 .000$ & $\$ 1.520 .344$ & $-\$$ & 213.656 \\
Central de Chile (V) (La Serena) & $\$ 1.734 .000$ & $\$ 1.520 .344$ & $-\$$ & 213.656 \\
Santo Tomás (Talca) & $\$ 1.687 .000$ & $\$ 1.520 .344$ & $-\$$ & 166.656 \\
Santo Tomás (V) (Santiago) & $\$ 1.680 .000$ & $\$ 1.520 .344$ & $-\$$ & 159.656 \\
Santo Tomás (Viña del Mar) & $\$ 1.637 .000$ & $\$ 1.520 .344$ & $-\$$ & 116.656 \\
Academia de Humanismo Cristiano & $\$ 1.615 .000$ & $\$ 1.520 .344$ & $-\$$ & 94.656 \\
Santo Tomás (Antofagasta) & $\$ 1.557 .000$ & $\$ 1.520 .344$ & $-\$$ & 36.656 \\
Santo Tomás (V) (Viña del Mar) & $\$ 1.485 .000$ & $\$ 1.485 .000$ & $\$$ & 0 \\
Santo Tomás (Iquique) & $\$ 1.430 .000$ & $\$ 1.430 .000$ & $\$$ & 0 \\
Santo Tomás (V) (Iquique) & $\$ 1.430 .000$ & $\$ 1.430000$ & $\$$ & 0 \\
Santo Tomás (V) (Antofagasta) & $\$ 1.415 .000$ & $\$ 1.415 .000$ & $\$$ & 0 \\
Santo Tomás (Los Ángeles) & $\$ 1.415 .000$ & $\$ 1.415 .000$ & $\$$ & 0 \\
\hline
\end{tabular}

* Vespertino (V)

En el otro extremo de las listas, hay pocos programas con aranceles bajo el referencial o sin diferencia los que, fundamentalmente, son impartidos por la Universidad Santo Tomás.

Tabla 7. Aranceles de programas de Psicología.

\begin{tabular}{lcccc}
\hline UNIVERSIDAD & ARANCEL REAL & $\begin{array}{c}\text { ARANCEL } \\
\text { REFERENCIA }\end{array}$ & DIFERENCIA \\
\hline Uniacc & $\$ 3.806 .000$ & $\$ 1.426 .061$ & $-\$ 2.379 .939$ \\
Diego Portales & $\$ 2.722 .109$ & $\$ 1.426 .061$ & $-\$ 1.296 .048$ \\
Nacional Andrés Bello (Santiago) & $\$ 2.719 .600$ & $\$ 1.426 .061$ & $-\$ 1.293 .539$ \\
Nacional Andrés Bello (Viña del Mar) & $\$ 2.719 .600$ & $\$ 1.426 .061$ & $-\$ 1.293 .539$ \\
Del Pacífico (Central) & $\$ 2.650 .000$ & $\$ 1.426 .061$ & $-\$ 1.223 .939$ \\
Central de Chile (Santiago) & $\$ 2.628 .000$ & $\$ 1.426 .061$ & $-\$ 1.201 .939$ \\
Adolfo Ibáñez (Santiago) & $\$ 2.875 .978$ & $\$ 1.717 .894$ & $-\$ 1.158 .084$ \\
Mayor (Santiago) & $\$ 2.490 .000$ & $\$ 1.426 .061$ & $-\$ 1.063 .939$ \\
Adolfo Ibáñez (Viña del Mar) & $\$ 2.516 .480$ & $\$ 1.717 .894$ & $-\$ 798.586$ \\
Santo Tomás (Santiago) & $\$ 1.990 .000$ & $\$ 1.426 .061$ & $-\$ 563.939$ \\
Alberto Hurtado & $\$ 2.247 .200$ & $\$ 1.717 .894$ & $-\$ 5$ & 529.306 \\
Mayor (Temuco) & $\$ 1.945 .000$ & $\$ 1.426 .061$ & $-\$ 518.939$ \\
De Viña del Mar (Viña del Mar) & $\$ 1.900 .000$ & $\$ 1.426 .061$ & $-\$ 4$ & 473.939 \\
Santo Tomás (V) (Santiago) & $\$ 1.890 .000$ & $\$ 1.426 .061$ & $-\$ 463.939$ \\
Central de Chile (Antofagasta) & $\$ 1.800 .000$ & $\$ 1.426 .061$ & $-\$ 373.939$ \\
Central de Chile (La Serena) & $\$ 1.734 .000$ & $\$ 1.426 .061$ & $-\$ 307.939$
\end{tabular}




\begin{tabular}{llllrr} 
Santo Tomás (Viña del Mar) & $\$ 1.697 .000$ & $\$ 1.426 .061$ & $-\$ 270.939$ \\
Academia de Humanismo Cristiano & $\$ 1.646 .600$ & $\$ 1.426 .061$ & $-\$$ & 220.539 \\
Santo Tomás (Talca) & $\$ 1.617 .000$ & $\$ 1.426 .061$ & $-\$$ & 190.939 \\
Santo Tomás (Antofagasta) & $\$ 1.557 .000$ & $\$ 1.426 .061$ & $-\$$ & 130.939 \\
Santo Tomás (Concepción) & $\$ 1.557 .000$ & $\$ 1.426 .061$ & $-\$$ & 130.939 \\
Academia de Humanismo Cristiano (V) & $\$ 1.547 .000$ & $\$ 1.426 .061$ & $-\$$ & 120.939 \\
Santo Tomás (La Serena) & $\$ 1.547 .000$ & $\$ 1.426 .061$ & $-\$$ & 120.939 \\
Católica Cardenal Raúl Silva Henríquez & $\$ 1.526 .000$ & $\$ 1.426 .061$ & $-\$$ & 99.939 \\
Santo Tomás (Temuco) & $\$ 1.515 .000$ & $\$ 1.426 .061$ & $-\$$ & 88.939 \\
Santo Tomás (V) (Temuco) & $\$ 1.515 .000$ & $\$ 1.426 .061$ & $-\$$ & 88.939 \\
Santo Tomás (Puerto Montt) & $\$ 1.505 .000$ & $\$ 1.426 .061$ & $-\$$ & 78.939 \\
Santo Tomás (Iquique) & $\$ 1.455 .000$ & $\$ 1.426 .061$ & $-\$$ & 28.939 \\
Santo Tomás (V) (Iquique) & $\$ 1.455 .000$ & $\$ 1.426 .061$ & $-\$$ & 28.939 \\
Santo Tomás (Osorno) & $\$ 1.455 .000$ & $\$ 1.426 .061$ & $-\$$ & 28.939 \\
Santo Tomás (Los Ángeles) & $\$ 1.415 .000$ & $\$ 1.415 .000$ & $\$$ & 0 \\
Santo Tomás (V) (Arica) & $\$ 1.315 .000$ & $\$ 1.315 .000$ & $\$$ & 0 \\
\hline
\end{tabular}

* Vespertino (V)

Algo a dilucidar en el futuro es cuántos estudiantes de esas instituciones resultan favorecidos con créditos o, viceversa, cuántos de los potenciales beneficiados se matricularán en dichas universidades. Asimismo, habrá que monitorear hasta dónde las instituciones se hacen cargo de cubrir la diferencia entre arancel real y de referencia, y el impacto financiero de esa decisión para ellas. Por el momento, es lógico suponer que algunas universidades siguen sin ser una alternativa viable para estudiantes imposibilitados de asumir individualmente el pago de la brecha.

\section{Universidades del CRUCH}

Los gráficos comparados de la sección I ilustraban el porcentaje considerable de carreras impartidas por las universidades del CRUCH, cuyo valor supera el 10 y el 20\% de diferencia entre arancel real y de referencia. Ello se refleja en los siguientes datos:

\begin{tabular}{lccl}
\hline Diferencia en pesos (arancel referencia - arancel real) & \\
\hline Diferencia promedio & $-\$ 275.717$ & \\
Máxima diferencia negativa & $-\$ 1.162 .713$ & Medicina (Universidad de Concepción) \\
Máxima diferencia positiva & $\$$ & 367.015 & Ingeniería (PUC) \\
\hline Diferencia porcentual (arancel referencia - arancel real en \% del arancel real \\
\hline Diferencia promedio & $-15,96 \%$ & \\
Máxima diferencia negativa & $-41,50 \%$ & \\
Máxima diferencia positiva & $19,80 \%$ & \\
\hline
\end{tabular}


Del análisis más detallado por institución emergen otros resultados. Uno de ellos es que la Pontificia Universidad Católica de Chile (PUC) es, por amplio margen, la que ostenta el promedio más alto de diferencia entre el precio real y el referencial, aun cuando ofrece, en menor proporción, carreras con un cobro más cercano al arancel de referencia. En efecto, el 73\% de las carreras de la PUC está en el quintil ${ }^{\mathrm{vi}}$ más caro de precios entre el total de programas que imparten las universidades del CRUCH, en contraste con muchas universidades regionales sin carreras en ese quintil (Universidad de Atacama). Así lo muestra la siguiente tabla, que, además, exhibe el ordenamiento de las universidades del $\mathrm{CRUCH}$ de acuerdo con la diferencia promedio de los programas que ofrecen respecto del arancel de referencia. Obsérvese la distancia entre la diferencia mayor, \$ 522.000 en la Pontificia Universidad Católica de Chile, y la menor, de la Universidad de Atacama con \$ 83.940. En cualquier caso, las brechas de la mayoría de las instituciones son significativas considerando que se trata de promedios.

Tabla 8. Diferencias absolutas y porcentuales entre arancel real y de referencia.

\begin{tabular}{lccc}
\hline UNIVERSIDAD & DIF MEDIA EN \$ & DIF. MEDIA EN \% & PROGRAMAS \\
\hline Pontificia Univ. Católica de Chile & $-\$ 522.117$ & $-21,0$ & 33 \\
Austral & $-\$ 470.372$ & $-23,2$ & 38 \\
De Antofagasta & $-\$ 418.535$ & $-24,5$ & 27 \\
Católica del Norte & $\$ 406.016$ & $-22,6$ & 30 \\
De Magallanes & $-\$ 379.647$ & $-21,6$ & 24 \\
Católica de Temuco & $-\$ 374.215$ & $-23,9$ & 23 \\
De Concepción & $-\$ 330.036$ & $-16,5$ & 75 \\
De Santiago & $-\$ 297.443$ & $-16,4$ & 57 \\
Pontificia Univ. Católica de Valparaíso & $-\$ 292.201$ & $-16,5$ & 51 \\
De Valparaíso & $-\$ 281.571$ & $-16,3$ & 67 \\
De Tarapacá & $-\$ 267.526$ & $-17,1$ & 38 \\
De Talca & $-\$ 253.777$ & $-13,6$ & 20 \\
Téc. Federico Sta. María & $-\$ 251.379$ & $-15,7$ & 51 \\
De Chile & $-\$ 249.668$ & $-12,2$ & 52 \\
Católica del Maule & $-\$ 248.758$ & $-15,6$ & 15 \\
De La Serena & $-\$ 235.553$ & $-16,1$ & 29 \\
Tecnológica Metropolitana & $-\$ 226.432$ & $-15,4$ & 28
\end{tabular}

vi Se trata de un quintil de precios entre todas las carreras de estas instituciones, que fue diseñado especialmente en este estudio para el análisis de los datos. 
De Los Lagos

Metropolitana de Ciencias de la Educación Arturo Prat

Del Bío Bío

De Concepción

De La Frontera

De Playa Ancha

De Atacama

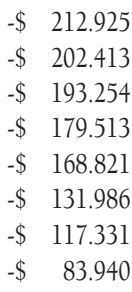

$\begin{array}{rr}-\$ & 212.925 \\ -\$ & 202.413 \\ -\$ & 193.254 \\ -\$ & 179.513 \\ -\$ & 168.821 \\ -\$ & 131.986 \\ -\$ & 117.331 \\ -\$ & 83.940\end{array}$

$-18,1$

25

25

31

37

21

29

43

29

Para las universidades del CRUCH se seleccionaron las mismas tres carreras de las llamadas "tradicionales". Una comparación dentro de este grupo de instituciones permite apreciar, en primer lugar, fuertes variaciones entre los precios mínimos y máximos (90\% en Derecho, 100\% en Psicología y 134\% en Ingeniería).

Tabla 9. Aranceles de programas de Derecho.

\begin{tabular}{lcccc}
\hline UNIVERSIDAD & ARANCEL REAL & $\begin{array}{c}\text { ARANCEL } \\
\text { REFERENCIA }\end{array}$ & DIFERENCIA \\
\hline Pontificia Univ. Católica de Chile & $\$ 2.780 .000$ & $\$ 2.086 .594$ & $-\$$ & 693.406 \\
Pontificia Univ. Católica de Valparaíso & $\$ 2.209 .000$ & $\$ 1.646 .934$ & $-\$$ & 562.066 \\
Católica del Norte & $\$ 1.940 .000$ & $\$ 1.400 .847$ & $-\$$ & 539.153 \\
Austral & $\$ 2.100 .000$ & $\$ 1.597 .326$ & $-\$$ & 502.674 \\
Católica de Temuco & $\$ 2.021 .600$ & $\$ 1.520 .344$ & $-\$$ & 501.256 \\
De Magallanes & $\$ 2.147 .000$ & $\$ 1.653 .996$ & $-\$$ & 493.004 \\
De Antofagasta & $\$ 1.950 .000$ & $\$ 1.458 .450$ & $-\$$ & 491.550 \\
De Concepción & $\$ 2.093 .000$ & $\$ 1.604 .828$ & $-\$$ & 488.172 \\
De Chile & $\$ 2.256 .000$ & $\$ 1.829 .428$ & $-\$$ & 426.572 \\
De Talca & $\$ 1.838 .000$ & $\$ 1.556 .808$ & $-\$$ & 281.192 \\
De Atacama & $\$ 1.690 .000$ & $\$ 1.439 .402$ & $-\$$ & 250.598 \\
Católica de la Santísima Concepción & $\$ 1.743 .000$ & $\$ 1.520 .344$ & $-\$$ & 222.656 \\
Arturo Prat & $\$ 1.668 .000$ & $\$ 1.458 .450$ & $-\$$ & 209.550 \\
De Tarapacá (Iquique) & $\$ 1.650 .000$ & $\$ 1.458 .450$ & $-\$$ & 191.550 \\
De Valparaíso & $\$ 1.660 .000$ & $\$ 1.488 .286$ & $-\$$ & 171.714 \\
De Tarapacá (Arica) & $\$ 1.458 .000$ & $\$ 1.458 .450$ & $\$$ & 450 \\
\hline
\end{tabular}

En cerca de dos tercios de las universidades se observan diferencias de más de $\$ 400.000$ entre el arancel real y de referencia para la carrera de Derecho. Por otra parte, la tendencia en el caso de Psicología es a una brecha menor, observándose incluso un caso en que el arancel cobrado coincide con el referencial, como se constata en la siguiente tabla: 
Tabla 10. Aranceles de programas de Psicología.

\begin{tabular}{lccccc}
\hline UNIVERSIDAD & ARANCEL REAL & $\begin{array}{c}\text { ARANCEL } \\
\text { REFERENCIA }\end{array}$ & DIFERENCIA \\
\hline Pontificia Univ. Católica de Chile & $\$ 2.780 .000$ & $\$ 2.086 .594$ & $-\$$ & 693.406 \\
Pontificia Univ. Católica de Valparaíso & $\$ 2.209 .000$ & $\$ 1.717 .894$ & $-\$$ & 491.106 \\
Austral & $\$ 2.100 .000$ & $\$ 1.621 .935$ & $-\$$ & 478.065 \\
Católica del Norte & $\$ 1.760 .000$ & $\$ 1.340 .680$ & $-\$$ & 419.320 \\
De Magallanes & $\$ 2.116 .000$ & $\$ 1.744 .390$ & $-\$$ & 371.610 \\
De Talca & $\$ 1.946 .500$ & $\$ 1.621 .935$ & $-\$$ & 324.565 \\
De La Serena & $\$ 1.720 .000$ & $\$ 1.426 .061$ & $-\$$ & 293.939 \\
De Concepción & $\$ 1.826 .000$ & $\$ 1.532 .659$ & $-\$$ & 293.341 \\
Del Bío-Bío & $\$ 1.720 .000$ & $\$ 1.435 .469$ & $-\$$ & 284.531 \\
De Tarapacá (Iquique) & $\$ 1.650 .000$ & $\$ 1.426 .061$ & $-\$$ & 223.939 \\
Católica del Maule & $\$ 1.728 .000$ & $\$ 1.505 .283$ & $-\$$ & 222.717 \\
De Valparaíso & $\$ 1.600 .000$ & $\$ 1.444 .454$ & $-\$$ & 155.546 \\
De La Frontera & $\$ 1.500 .000$ & $\$ 1.358 .700$ & $-\$$ & 141.300 \\
De Santiago de Chile & $\$ 1.737 .500$ & $\$ 1.609 .853$ & $-\$$ & 127.647 \\
Arturo Prat & $\$ 1.488 .000$ & $\$ 1.426 .061$ & $-\$$ & 61.939 \\
De Chile & $\$ 1.653 .000$ & $\$ 1.621 .935$ & $-\$$ & 31.065 \\
De Tarapacá (Arica) & $\$ 1.386 .000$ & $\$ 1.386 .000$ & $\$$ & 0 \\
\hline
\end{tabular}

Al analizar los aranceles de la carrera de Ingeniería Comercial, las diferencias entre los valores reales y de referencia se agudizan, apreciándose dos casos de instituciones donde la brecha supera los $\$ 700$ mil.

Tabla 11. Aranceles de programas de Ingeniería Comercial.

\begin{tabular}{lcccc}
\hline UNIVERSIDAD & ARANCEL REAL & $\begin{array}{c}\text { ARANCEL } \\
\text { REFERENCIA }\end{array}$ & DIFERENCIA \\
\hline Pontificia Univ. Católica de Chile & $\$ 3.250 .000$ & $\$ 2.312 .015$ & $-\$$ & 937.985 \\
De Chile & $\$ 2.639 .000$ & $\$ 1.937 .345$ & $-\$$ & 701.655 \\
De Magallanes & $\$ 2.147 .000$ & $\$ 1.530 .533$ & $-\$$ & 616.467 \\
Católica del Norte & $\$ 1.940 .000$ & $\$ 1.340 .680$ & $-\$$ & 599.320 \\
Pontificia Univ. Católica de Valparaíso & $\$ 2.209 .000$ & $\$ 1.646 .934$ & $-\$$ & 562.066 \\
De Concepción & $\$ 2.132 .000$ & $\$ 1.612 .657$ & $-\$$ & 519.343 \\
De Santiago de Chile & $\$ 2.270 .600$ & $\$ 1.755 .877$ & $-\$$ & 514.723 \\
Técnica Federico. Sta. María (Santiago) & $\$ 2.148 .000$ & $\$ 1.637 .520$ & $-\$$ & 510.480 \\
Austral & $\$ 2.100 .000$ & $\$ 1.597 .326$ & $-\$$ & 502.674 \\
Técnica Federico. Sta. María (Valparaíso) & $\$ 1.988 .000$ & $\$ 1.539 .538$ & $-\$$ & 448.462 \\
De Valparaíso (Santiago) & $\$ 1.740 .000$ & $\$ 1.396 .463$ & $-\$$ & 343.537 \\
De Valparaíso (Melipilla) & $\$ 1.600 .000$ & $\$ 1.283 .001$ & $-\$ 1$ & 316.999 \\
Arturo Prat & $\$ 1.533 .000$ & $\$ 1.239 .198$ & $-\$ 293.802$ \\
De La Serena & $\$ 1.720 .000$ & $\$ 1.438 .612$ & $-\$ 281.388$ \\
De Tarapacá & $\$ 1.386 .000$ & $\$ 1.183 .164$ & $-\$ 202.836$
\end{tabular}




\begin{tabular}{llllrr} 
De Talca & $\$ 1.730 .000$ & $\$ 1.539 .538$ & $-\$$ & 190.462 \\
De Valparaíso (Valparaíso) & $\$ 1.600 .000$ & $\$ 1.432 .993$ & $-\$$ & 167.007 \\
Católica de la Santísima Concepción & $\$ 1.676 .500$ & $\$ 1.520 .344$ & $-\$$ & 156.156 \\
De La Frontera & $\$ 1.708 .000$ & $\$ 1.563 .000$ & $-\$$ & 145.000 \\
Del Bío-Bío & $\$ 1.605 .000$ & $\$ 1.522 .500$ & $-\$$ & 82.500 \\
Tecnológica Metropolitana & $\$ 1.459 .343$ & $\$ 1.457 .094$ & $-\$$ & 2.249 \\
De Los Lagos & $\$ 1.154 .289$ & $\$ 1.390 .000$ & $\$$ & 235.711 \\
\hline
\end{tabular}

Nótese que algunas instituciones tienden a mostrar, en las tres carreras seleccionadas, las mayores distancias respecto de los aranceles fijados por el Ministerio. Ello ocurre, por ejemplo, con la Pontificia Universidad Católica de Chile, Pontificia Universidad Católica de Valparaíso, Universidad Austral de Chile y Universidad Católica del Norte.

Ahora bien, tratándose de las universidades del CRUCH que imparten una gran diversidad de carreras, cubriendo todas las áreas del conocimiento, es posible realizar un análisis acerca de las diferencias arancelarias según dichas áreas. Los datos en esta línea muestran que las áreas donde sus carreras tienen aranceles que distan más de los valores de referencia son salud, agropecuaria e ingenierías civiles. Los programas que muestran menores diferencias pertenecen a las pedagogías o bien son carreras técnicas o tecnológicas. 
Gráfico 3. Arancel medio en pesos; real y referencial.

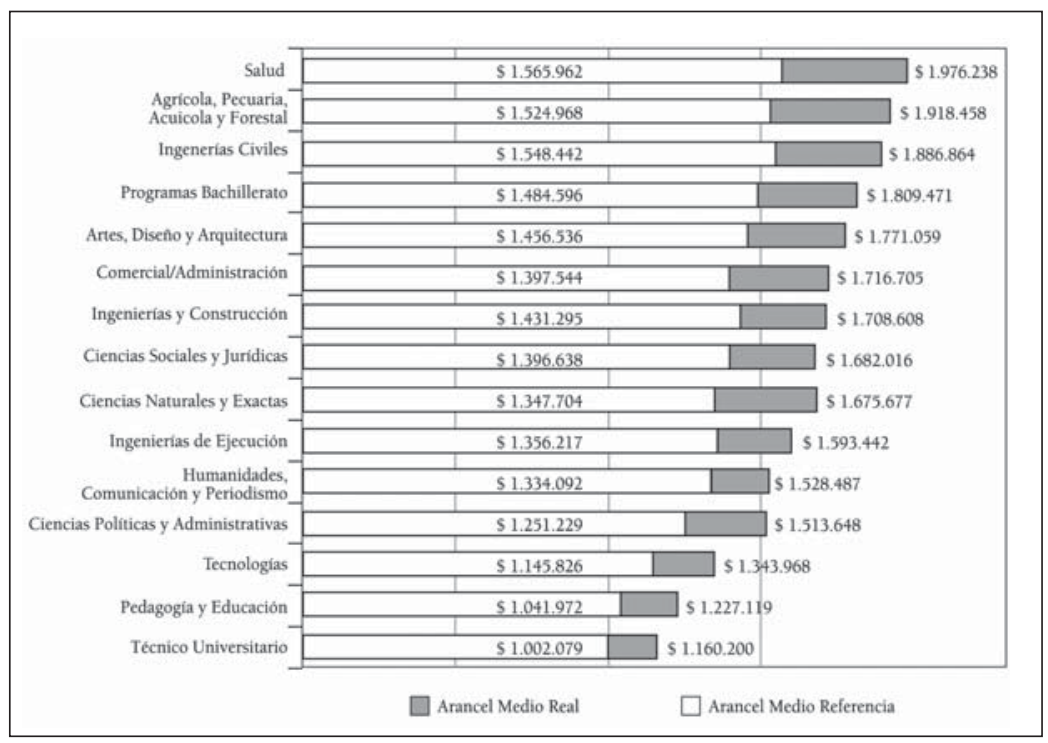

Los mayores aranceles que se cobran en los primeros casos podrían ser explicados, en alguna medida, por los elevados costos de infraestructura y equipamiento que tales carreras implican, lo que no siempre se reflejaría en el arancel referencial. Esto ameritaría una revisión de los indicadores para construir este último, que apunte a incluir ese tipo de variables. Por otro lado, carreras como Bachillerato, que no están asociadas a altos costos de implementación, muestran una diferencia promedio de $18 \%$ respecto del arancel de referencia, es decir, un arancel real relativamente alto en comparación con el referencial, lo que refuerza la explicación de que hay otras variables que atraviesan la fijación de precios además del costo de ejecución del programa.

\section{Conclusiones}

Ante la pregunta sobre la existencia de brechas entre aranceles reales de las carreras y aquellos fijados para la asignación de créditos, la respuesta es nítida: la distancia existe y su magnitud amerita mayores estudios acerca de su comportamiento entre instituciones y programas 
académicos, y en torno a sus eventuales impactos, tanto en el sistema de precios de la educación superior, como en los estudiantes y familias que requieren apoyo económico para financiar estos estudios.

Mientras tanto, y en una primera etapa de aplicación de este esquema de otorgamiento de créditos, la comparación entre los valores determinados por el MINEDUC y los cobrados por las instituciones arroja algunas situaciones interesantes que propician reflexiones y despiertan interrogantes.

La primera constatación general es que los precios para cursar estudios superiores muestran una tremenda diversidad, la que evidentemente no es recogida por los aranceles de referencia definidos.

Para efectos de las ayudas estudiantiles mediante créditos, el Estado optó por fijar un monto máximo de cobertura en un contexto de gran heterogeneidad de valores de las carreras, generándose brechas significativas para los estudiantes, de las que, en principio, nadie se hace cargo. Es posible interrogarse sobre la factibilidad de que un valor que es, por definición, referencial logre dar cuenta de un sistema diverso de precios y, entonces, si tiene sentido o no establecer un criterio que, aparentemente, no se está empleando como referencia por parte de las instituciones educativas. Pero también es cuestionable pensar en la supresión de dicho valor de referencia en la medida en que la carga monetaria que ello implicaría podría hacer inviable todo el sistema.

En el grupo de las universidades del CRUCH y de las privadas se encuentran aquellas instituciones cuyos aranceles originan las mayores diferencias respecto de los aranceles referenciales del Ministerio; no obstante, en las privadas se observan los valores que distan más de los montos de referencia.

En efecto, más de tres cuartos de las carreras ofrecidas por las universidades privadas tienen aranceles reales con una diferencia 
negativa respecto del arancel referencial mayor al 10\% y casi el 60 de ellas presenta aranceles con diferencias mayores al 20\%. Sólo el $10 \%$ tiene aranceles que coinciden con el referencial. De modo similar, casi el 80\% de los programas académicos del CRUCH tienen una diferencia negativa mayor al $10 \%$, poco menos de un tercio tiene una diferencia negativa mayor al $20 \%$ y el $0,5 \%$ cobra exactamente el arancel de referencia. Claramente, en estos dos grupos es donde la brecha no cubierta por los créditos es más significativa y se aprecia la menor cantidad de casos donde coinciden arancel real y arancel de referencia. Resulta interesante constatar que no sean sólo las privadas las que superan marcadamente los aranceles de referencia, sino algunas de las llamadas universidades tradicionales, comúnmente asociadas a una vocación más social y pública.

Por otra parte, en los grupos de universidades del CRUCH y en aquellos de las privadas se manifiesta una segmentación de precios que marca una clara distinción entre instituciones con precios altos, otras con valores medios y otras con aranceles relativamente bajos, lo que se aplica a la mayoría de sus carreras, con la excepción de algunos programas de ciertas áreas de conocimiento. Esta segmentación se reproduce en la distancia que se establece con el arancel de referencia.

Así, por ejemplo, se pudo observar la homogeneidad de los aranceles cobrados por la UNIACC en sus distintas carreras, las que se ubicaron en el extremo superior del ranking de las diferencias con el arancel referencial y el mismo fenómeno para la Universidad Santo Tomás cuyos aranceles tienden a acercarse a los de referencia. Análogamente, las mismas carreras ofrecidas por universidades diferentes muestran precios muy distintos. En otras palabras, el precio del arancel real es, muchas veces, una característica institucional y no siempre de la carrera en sí misma, al igual que lo será la brecha generada respecto del monto máximo del crédito que se otorga a sus alumnos. Sin perjuicio de ello, en el caso de los programas de las 
áreas de salud y agropecuaria los aranceles reales son consistentemente más altos que en el resto de las carreras de una institución determinada y, por lo tanto, allí se concentra el mayor déficit de la cobertura predeterminada de créditos para esas carreras.

Relacionado con lo anterior, universidades que, de acuerdo con los indicadores aplicados por el MINEDUC, se ubicaron en el mismo tramo de instituciones para efectos de la fijación de aranceles de referencia, exhiben valores reales de sus carreras significativamente distantes entre instituciones.

Además de los casos de las universidades Santo Tomás y UNIACC, que fueron clasificadas por el Ministerio en el grupo D, es posible apreciar en cada uno de dichos grupos una dispersión considerable de los aranceles reales dependiendo de las instituciones que los dicten. Así, las universidades Adolfo Ibáñez y Alberto Hurtado, las únicas dos privadas ubicadas en el tramo B, se distancian en cuanto a los valores efectivamente cobrados, pues la primera supera por mucho los aranceles de referencia, mientras que la segunda los excede en bastante menor medida. También ocurre esto con la Universidad de Chile, que presenta aranceles más cercanos al referencial que la Pontificia Universidad Católica de Chile, aun estando ambas en el grupo A de la calificación ministerial. Situación similar ocurre con los aranceles de los IP y los CFT analizados, en los casos de los institutos INACAP y DuocUC que se ubican en grupo A.

Dentro del grupo de universidades del CRUCH, se aprecia bastante dispersión en cuanto a la diferencia entre sus aranceles y los valores referenciales, destacando algunas instituciones que se alejan particularmente de los promedios.

A pesar de pertenecer sus autoridades a un Consejo que las agrupa, las universidades del CRUCH evidencian una fijación 
bastante autónoma y diversa de los valores de sus aranceles. Claramente, la Pontificia Universidad Católica de Chile es la institución que presenta el más alto promedio de diferencia entre el precio real y referencial, mientras que la Universidad de Atacama es la que muestra la diferencia menor. El análisis por quintil de carreras según aranceles arroja que el $73 \%$ de las carreras de la PUC está en el quintil más caro del total de programas que imparten las universidades del CRUCH. Ello, en contraste con muchas de estas universidades que no ofrecen carreras con ese nivel de costo.

Hay pocas universidades cuyas carreras tienden a cobrar valores bajo los montos referenciales o cercanos a ellos.

Sin perjuicio de la tendencia de los aranceles de las universidades a estar por encima del arancel de referencia, se observan, en una proporción menor, programas que cobran montos más bajos o similares al arancel referencial, los que, además, pertenecen consistentemente a determinadas instituciones. Esto refuerza la idea de la segmentación de instituciones y de precios, a pesar de la diversidad general del sistema, y despierta la interrogante acerca de qué es lo que distingue a estas instituciones cuyos aranceles coinciden con los máximos definidos por el Estado o incluso son menores a ellos.

Por otra parte, las carreras ofrecidas por los IP y los CFT elegibles para recibir alumnos con crédito tienen valores que no distan tanto de los aranceles de referencia, aun cuando, en los casos de algunas instituciones, se observan diferencias inesperadas entre las mismas carreras.

Los precios de los programas impartidos por los CFT y los IP se acercan más a los aranceles fijados por el Ministerio, estando varias carreras en el mismo valor que definió este último y desvaneciéndose en esos casos la brecha no cubierta por el crédito. En efecto, casi el 
$20 \%$ de las carreras de CFT y el $15 \%$ de las carreras de IP tienen un arancel igual al valor de referencia. A pesar de ello, destacaron casos de instituciones de mayor tamaño y expansión territorial que han establecido aranceles reales muy disímiles entre sedes para una misma carrera (incluso en sedes de una misma ciudad), como se observó especialmente en la oferta de INACAP y de DuocUC, lo que no está reflejado en los aranceles de referencia fijados para estos programas en la medida en que dichos aranceles no discriminan entre todas estas sedes. A pesar de ello, los casos de carreras donde la diferencia por sede es de magnitud son reducidos y, a su vez, los aranceles referenciales propician una diferencia positiva para las sedes regionales, al estar determinados en función de los valores de la Región Metropolitana que son más elevados. En consecuencia, no se trataría de una situación que afecte al grueso del alumnado.

Sin embargo, todos estos hallazgos, en su conjunto, exhiben una realidad de inmensa diversificación de valores de carreras y, en consecuencia, una heterogeneidad en la magnitud de las brechas con el arancel referencial, incluso entre programas que en principio debieran tener características similares. Es evidente que la fijación del valor por cursar estudios superiores no remite sólo a variables como costos de implementación de las carreras, sino a otros aspectos como podrían ser el prestigio de la institución que las imparte, las expectativas de ingreso para los futuros titulados de una determinada carrera, la población socioeconómica objetivo a la que apunta el programa o la institución, entre otros. Si bien es esperable que este tipo de factores intervenga en la determinación de precios de la educación, en la medida en que el sistema, ante todo, es reconocido como un sistema de mercado, llama la atención la aguda segmentación en la base de esta diversidad, que origina brechas respecto del monto de referencia, las cuales, en algunos casos, equivaldrían aproximadamente a pagar un arancel promedio por parte del estudiante. Surgen entonces las preguntas: ¿de acuerdo con qué criterios o variables las instituciones de educación superior definen los aranceles de las carreras que ofrecen y de qué manera se consideraron para el año en curso los valores fijados por el MINEDUC? 
Pues bien, en este marco de heterogeneidad, la fijación de cualquier tipo de monto de referencia, más allá de los niveles de precisión que el referente pueda alcanzar, tiene consecuencias significativas de distinto tipo que ameritan ser examinadas de manera más específica. De partida, parece clave que cualquier análisis futuro sobre el impacto de las condiciones para acceder a beneficios tome en consideración cuántos estudiantes realmente reciben apoyo mediante créditos con aval estatal y por qué vías se cubren las diferencias que pudieran darse entre el préstamo y el precio que fija cada institución. Un factor adicional a considerar es la contribución institucional a través de becas y otras ayudas estudiantiles que sería pertinente ponderar en conjunto con los antecedentes entregados por este estudio.

Sin perjuicio de ello, la diferencia, mayor o menor, entre el costo real de estudiar y el monto máximo de los créditos, seguirá existiendo para una masa significativa de estudiantes, pudiendo preverse que se mantendrá la presión de hacerse cargo de esta brecha y la discusión sobre quién debiera hacerse cargo de ella.

\section{Bibliografía}

Ministerio de Educación (2005) Criterios para la Construcción de un Arancel de Referencia. Santiago de Chile: MINEDUC.

Salas, Víctor y Aranda, Rodrigo. (2004) Estructura, Diferenciación y Convergencia de los Aranceles Universitarios. Estudios Sociales, 113.

Recibido: 5 de junio de 2006

Aceptado: 15 de junio de 2006

Nota: Gráficos y tablas que complementan los datos proporcionados en este artículo están incorporados en el sitio en internet del CSE: http://www.cse.cl 